\title{
Erratum to: Fuzzy soft set-based approach to prioritizing technical attributes in quality function deployment
}

\author{
Zhihui Yang $\cdot$ Yizeng Chen
}

Published online: 29 November 2012

(C) Springer-Verlag London 2012

\section{Erratum to: Neural Comput \& Applic}

DOI 10.1007/s00521-012-1201-1

Unfortunately, in the original publication, the corresponding authors' name was incorrectly published as Yizhen Chen. The correct name should read as Yizeng Chen. 